\title{
Research on Electricity Trading Evaluation System Based on the Improved Entropy-TOPSIS
}

\author{
Lin GUO ${ }^{1}$, Chao MA ${ }^{1}$, Jun-mei WANG ${ }^{1}$, Lei WANG ${ }^{2}$, Chun-cheng GAO ${ }^{2}$ and Shu-hong SHI ${ }^{2}$ \\ ${ }^{1}$ State Grid Chongqing Electric Power Corporation Yuzhong District, Chongqing 400014, China \\ ${ }^{2}$ Nari Group Corporation/State Grid Electric Power Research Institute, Nanjing 211006, Jiangsu Province, China \\ gaochuncheng@sgepri.sgcc.com.cn
}

\begin{abstract}
The assessment of electricity trading business is an effective tool for electric market analysis and power regulation, which has an important guiding significance to the development and optimization of business. This paper constructs an evaluation index system which consists of three indices, each indicating a key aspect of the electricity trading business, as well as index weights for weighting the calculated indices. The three indices include energy saving benefit, trading carbon reduction performance and fulfilment rate of non-water renewable energy quota. A trading evaluation model based on an improved entropy-TOPSIS method is constructed for calculating these indices along with the weights. The proposed index systems and models are suggested to be reasonable from a case study of evaluating comprehensive costs of electricity trading business of a jurisdictional province in China.
\end{abstract}

Index Terms - Electricity trading business; evaluation index; evaluation model; improved TOPSIS; entropy method.

\section{Introduction}

The comprehensive construction of smart grid and the rapid development of UHV Technology make the types and objects of power trading become more complex and diverse [1]. There is more uncertainty of transaction behavior. The Renewable energy quotas promote electricity trading evaluation work need to comprehensive analysis on the environmental impact of transactions. Therefore, it is necessary to establish comprehensive electricity trading evaluation index system for deep analysis and exploration of the transaction data, which is in line with the actual situation of the current power grid.

An evaluation system including market efficiency, market structure, system balancing and grid electricity market operating conditions was proposed for the USA PJM Market [2]. Key indicators to assess the efficiency of electricity markets based on resource allocation state, the producer and the consumer surplus and increment are put forward in [3]. A grey correlation model, and analyzed the correlation between the evaluation of power market efficiency and influence factors are established in [4]. At present, there is no widely recognized evaluation system power trading business considering the development of renewable energy, and no effective and comprehensive evaluation model and method to conduct a scientific and rational assessment on transaction work at home and abroad.

The paper puts forward the evaluation index system of electricity trading business and constructs the improved Entropy-TOPSIS evaluation model for comprehensive evaluation combined with the electric power market transaction characteristics and renewable energy development goals. Finally, for a province electricity trading business to carry out simulation analysis, the calculation results show that the index system and proposed method are reasonable and feasible.

\section{The Evaluation Index System of Electricity Trading Business}

Using the analytic hierarchy process to build the index system, five first-level indicators are included, which are established for indicating, respectively, the balance between supply and demand, transaction organizations, transaction plan, transaction settlement and environmental benefits. What is more, 21 second-level indexes such as trade consumption performance, can be used to effectively evaluate the power trading. Indicators framework as shown in Figure.1.

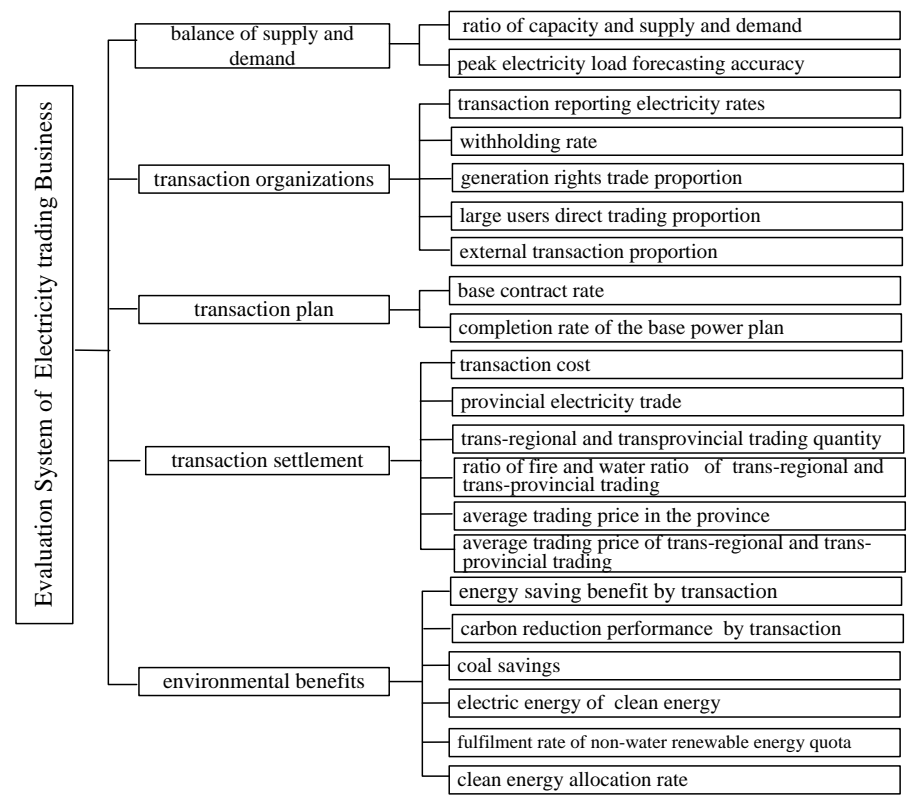

Fig.1 Evaluation index system on electricity trading business

Those indicators whose concepts have been defined or discussed clearly in [2-7] are not repeated to present here for conciseness. Thus, the remaining indices are explained as follows: 


\section{A. Energy saving benefit by transaction}

The index is defined as the ratio of the energy consumption reduction by electricity trading and local GDP. The formula is:

$$
P_{\text {energy }}=C_{s} / G D P_{L} \text {. }
$$

Where $P_{\text {energy }}$ denotes energy saving benefit, $G D P_{L}$ the local GDP and $C_{p}$ the energy consumption reduction due to electricity trading.

\section{B. Carbon reduction performance by transaction}

The index is defined as the ratio of the $\mathrm{CO} 2$ emission reduction by electricity trading and local GDP. The formula is:

$$
P_{\mathrm{co}_{2}}=I_{s} / G D P_{L} .
$$

Where $P_{c o 2}$ is transaction carbon reduction performance, $I_{s}$ is $\mathrm{CO}_{2}$ emission reduction due to electricity trading.

\section{Fulfilment rate of non-water renewable energy quota}

According to the long-term development goal and planning of the national renewable energy, renewable energy quota is the lowest non-hydro renewable energy power consumption ratio index in view of the whole society electricity consumption of the provincial administrative area[8]. The fulfilment rate of non-water renewable energy quota is the ratio of actual fulfilment and the target of non water renewable energy quota.

$$
a=\left(\mathrm{p}_{\text {non-h }} / \mathrm{p}_{\mathrm{e}}\right) / k .
$$

Where $\alpha$ represents the non-hydro renewable energy quota fulfillment rate, $p_{e}$ is the target value, $k$ is total electricity consumption, $p_{n o n-h}$ is non water renewable energy power consumption. The higher is the value of $\alpha$, the better the fulfilment of regional quota is.

\section{Comprehensive Evaluation of Power Trading Business Based on Improved Entropy -TOPSIS}

A. Determination of the index weight by an improved entropy method

The traditional entropy method is unable to directly utilized to calculate both negative and extreme values[9], So in this paper standardized methods are used to improve the traditional entropy method, by eliminating the influence of the negative and the extreme. The calculation process is as follows:

1) Translate data coordinate to eliminate the negative influence. Standardize index value $y_{i j}^{*}$ after translation turn into $y_{i j}^{\prime *}$ :

$$
y_{i j}^{\prime *}=y_{i j+\mathrm{t}}^{*} .
$$

2) Calculate the proportion $P_{i j}$ of the index value after being translated that is the contribution of the i-th program under the $\mathrm{j}$-th index property.

3) Calculate improved entropy of the $j$-th index:

$$
c_{j}=-\left(\frac{1}{\ln n}\right) \sum_{i=1}^{n} P_{i j} \ln P_{i j} .
$$

4) Calculate the difference coefficient $v_{j}$ and the weighting coefficient $w_{j}$ of the j-th index.

\section{B. Construction of the improved TOPSIS model to evaluate} indicators

Improved TOPSIS by the gray correlation method can describe the close degree between the ideal scheme and alternatives more exactly, and sort the merits of the program, so as to provide basis for decision making. The calculation process is as follows:

1) Calculate the weighted standardization matrix

Suppose $\mathrm{m}$ indicator programs are concerned to evaluate, $\mathrm{n}$ indexes are used for evaluation, the corresponding index values were $r_{i j}(i=1,2, \ldots, m ; j=1,2, \ldots, n)$. The standard index matrix is $R=\left(r_{i j}\right)_{m \times n}$. The index matrix after normalization by multiplying with the corresponding index weights can be obtained as the weighted standardized matrix Y.

2) Determine the positive and negative ideal solution

$$
\begin{aligned}
& Y_{0}^{+}=\left(\max Y_{l j}\left|j \in j^{+}\right|, \min Y_{l j}\left|j \in j^{-}\right|\right) \\
& Y_{0}^{-}=\left(\min Y_{l j}\left|j \in j^{+}\right|, \max Y_{l j}\left|j \in j^{-}\right|\right) . \\
& i=1, \ldots, m
\end{aligned}
$$
indicators.

Where $j^{+}$is forward indicators, $j^{-}$is negative

3) Calculate grey correlation degree

Provided that the gray correlation coefficient matrix of the programs and the positive ideal solution is $D^{+}$, then the grey correlation degree between the $\mathrm{i}$-th program and positive ideal solution is:

$$
D_{i}^{+}=\frac{1}{n} \sum_{j=1}^{n} \mu_{i j}^{+}, \quad(i=1,2, \cdots, 6) .
$$

Where $\mu_{i j}^{+}$is grey correlation coefficient for the $\mathrm{i}$-th program and the positive ideal solution with respect to the $\mathrm{j}$-th index.

Then, calculate the gray correlation coefficient matrix $\mathrm{D}^{-}$ of the programs and the negative ideal solution, so grey correlation between the $\mathrm{i}$-th program and negative ideal solution is:

$$
D_{i}^{-}=\frac{1}{n} \sum_{j=1}^{n} \mu_{i j}^{-}, \quad(i=1,2, \cdots, 6)
$$

Where $\mu_{i j}^{-}$is grey correlation coefficient for the i-th program and the negative ideal solution with respect to the $j$-th index.

4) Calculate grey relational approaching degree 


$$
Q_{i}=\frac{D_{i}^{+}}{D_{i}^{+}+D_{i}^{-}}, \quad(i=1,2, \cdots, 6) .
$$

5) Programs are sorted according to the $Q_{i}$ value The higher the $Q_{i}$ value, the better the solution.

\section{A Numerical Example}

Use electricity transaction data for analysis from January to June in 2014. The raw data of each index are shown in table 1:

TABLE I Raw data of indicator

\begin{tabular}{|c|c|c|c|c|c|c|}
\hline & January & February & March & April & May & June \\
\hline generation rights trade proportion $(\%)$ & 0.00 & 0.00 & 100.00 & 100.00 & 52.78 & 13.07 \\
\hline external transaction proportion $(\%)$ & 0.00 & 0.00 & 0.00 & 0.00 & 47.22 & 86.93 \\
\hline trans-regional and trans-provincial trading quantity(billion kilowatt hours) & 18.63 & 12.95 & 16.74 & 11.21 & 6.42 & 16.81 \\
\hline ratio of fire and water ratio of trans-regional and trans-provincial trading $(\%)$ & 97.88 & 271.40 & 383.81 & 176.39 & 549.81 & 1506.03 \\
\hline average trading price of trans-regional and trans-provincial trading(Yuan / MWh) & 392.23 & 357.60 & 355.52 & 360.76 & 325.20 & 320.99 \\
\hline saving performance by transaction (tone of coal/ Million yuan) & 0.00 & 0.00 & 7.28 & 3.42 & 7.56 & 8.90 \\
\hline carbon reduction performance by transaction(Tons / million yuan) & 0.00 & 0.00 & 18.93 & 8.90 & 19.67 & 23.13 \\
\hline fulfilment rate of non-water renewable energy quota $(\%)$ & 92.00 & 90.00 & 95.00 & 99.00 & 100.00 & 97.00 \\
\hline
\end{tabular}

To calculate the $w_{j}$, respectively is 0.085,0.076,0.105,0.104,0.073,0.099,0.088,0.094,0.092,0.095, 0.088 . The calculation result of positive ideal scheme is $(0.100$; $0.134 ; 0.103 ; 0.111 ; 0.142 ; 0.087 ; 0.136 ; 0.096 ; 0.099 ; 0.109$; $0.136)$, the negative ideal scheme is $(-0.079 ;-0.046 ;-0.174$; $0.169 ;-0.056 ;-0.148 ;-0.105 ;-0.108 ;-0.106 ;-0.133 ;-0.097)$. follows:

The calculation results of grey correlation degree are as

$$
D_{i}^{+}=[0.542 ; 0.419 ; 0.632 ; 0.490 ; 0.539 ; 0566]^{\mathrm{T}} ;{ }^{D_{i}^{-}}=[0.593 ;
$$
$0.672 ; 0436 ; 0.516 ; 0.506 ; 0565]^{\mathrm{T}}, \mathrm{i}=1,2,3,4,5,6$.

Grey correlation degree calculation results for the six months: $\mathrm{Q}_{1}=0.478 ; \mathrm{Q}_{2}=0.384 ; \mathrm{Q}_{3}=0.592 ; \mathrm{Q}_{4}=0.487 ; \mathrm{Q}_{5}=0.516$; $\mathrm{Q}_{6}=0.500$.

The greater the relatively is close to the target, the better the trading business development situation, additionally, the higher the environmental benefits. Therefore, comprehensive evaluation of the best is March, followed by May, June, April, January and February respectively. In March, the more heavily weighted indicators such as provincial electricity trade and trans-regional and trans-provincial trading quantity are tops in the counting of the index system, and bring the reduction of energy consumption and $\mathrm{CO} 2$ emissions due to the generation rights trade, so the optimal month is March. Therefore it is necessary to weigh the pros and cons of indicators performance of each month. The calculation results obtained via both the proposed method and the traditional TOPSIS are schematically shown in figure 3 for comparison.

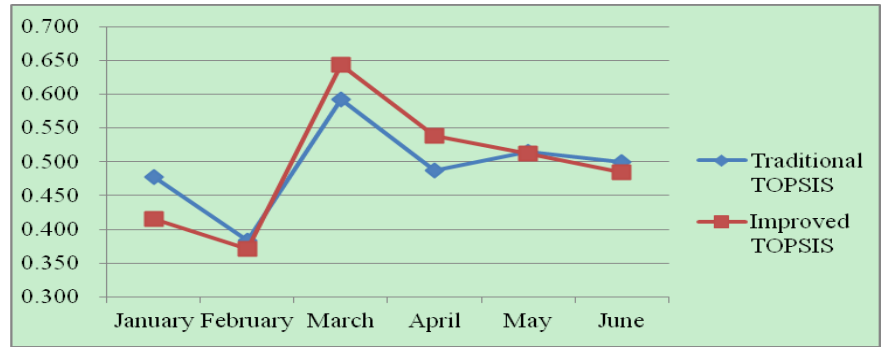

Fig.3 Comparison of computation

After evaluating the indices for the six months, it is found that no individual month with all the calculated indices being either best or worst exits to be distinct from the others, as a result, impartial conclusions about the performance of the trading of all the six months have to be traded off, according to each calcaulated indices. The calculated indices via both the proposed method and the traditional one are plotted in Fig.3.

\section{Conclusion}

(1) An evaluation index system of electric power transaction business are constructed, including saving performance, carbon reduction performance caused by trade and non-hydro renewable energy quota completion rates etc. The system can objectively reflect the actual situation of electricity trading, and better promote renewable energy use and consumptive.

(2)Agrid electricity trading business evaluation model based on improved entropy method -TOPSIS is built. This model can evaluate more scientifically and effectively for trading

(3)The power companies should pay full attention to the construction of a new indicator system and selection of 
evaluation methods on the basis of original key indicators such as electricity trading and transaction price, etc., in order to effectively analyze trading business development, and to provide a reference for the transaction optimization.

\section{Acknowledgment}

This work was financially supported by the Science and Technology Project of the China State Grid Corp (DZN17201300045). The author would like to thank all the people and institutions who have offered their help.

\section{References}

[1] SHEN Yang-wu, PENG Xiao-tao, MAO Xun, et al. Comprehensive Evaluation Indexes Framework and Evaluation Method on Location Layout of UHV Substations. Power System Technology, 2012, 36 (12): 44-54.

[2] Steven Craig Anderson. Analyzing strategic interaction in multisettlement electricity markets: A closed-loop supply function equilibrium model. Cambridge: Harvard University, 2004.
[3] WANGWei, SHAO Shan, LI Lei, et al. Efficiency Theory of Electricity Market and Its Evaluation Method. Power System Technology, 2009, 33 (14): 66-71.

[4] CHENG Cheng, LI Chun-jie. Application of Grey Incidence Analysis in the Regional Electricity Market Efficiency Evaluation. Journal of North China Electric Power University (Social Sciences), 2010 (3): 10-13.

[5] WANG Qin, WEN Fu-shuan, LIU Min, et al. Development of Evaluation Indices System for Power Market. Electric Power Technologic Economics, 2008, 20 (5): 21-27.

[6] LONG Su-yan, YANG Zheng-lin, GENG Jian, et al. Trans-regional and Transprovincial Trading Control Indices and Control Platform Technology. Automation of Electric Power Systems, 2014, 38 (13): 108115.

[7] LIU Rui-feng, LIU Wei-gang, ZHANG Wen, et al. Economic Evaluation of the Trans-Provincial and Trans-Regional Renewable Energy Trading Based on the Renewable Energy Quota System. Power System and Clean Energy, 2014, 30 (1): 59-63.

[8] LU Jian-chang, JIANG Wei, LIU Na. Study on Credit Evaluation of Power Consumers Based on Improved Entropy. Journal of Electric Power, 2008, 23 (5): 368-370.

[9] LIN Ji-keng, LI Tong-fei, ZHAO Zi-ming. Assessment on Power System Black-Start Schemes Based on Entropy-Weighted Fuzzy Comprehensive Evaluation Model. Power System Technology, 2012, 36 (2): 115-120. 